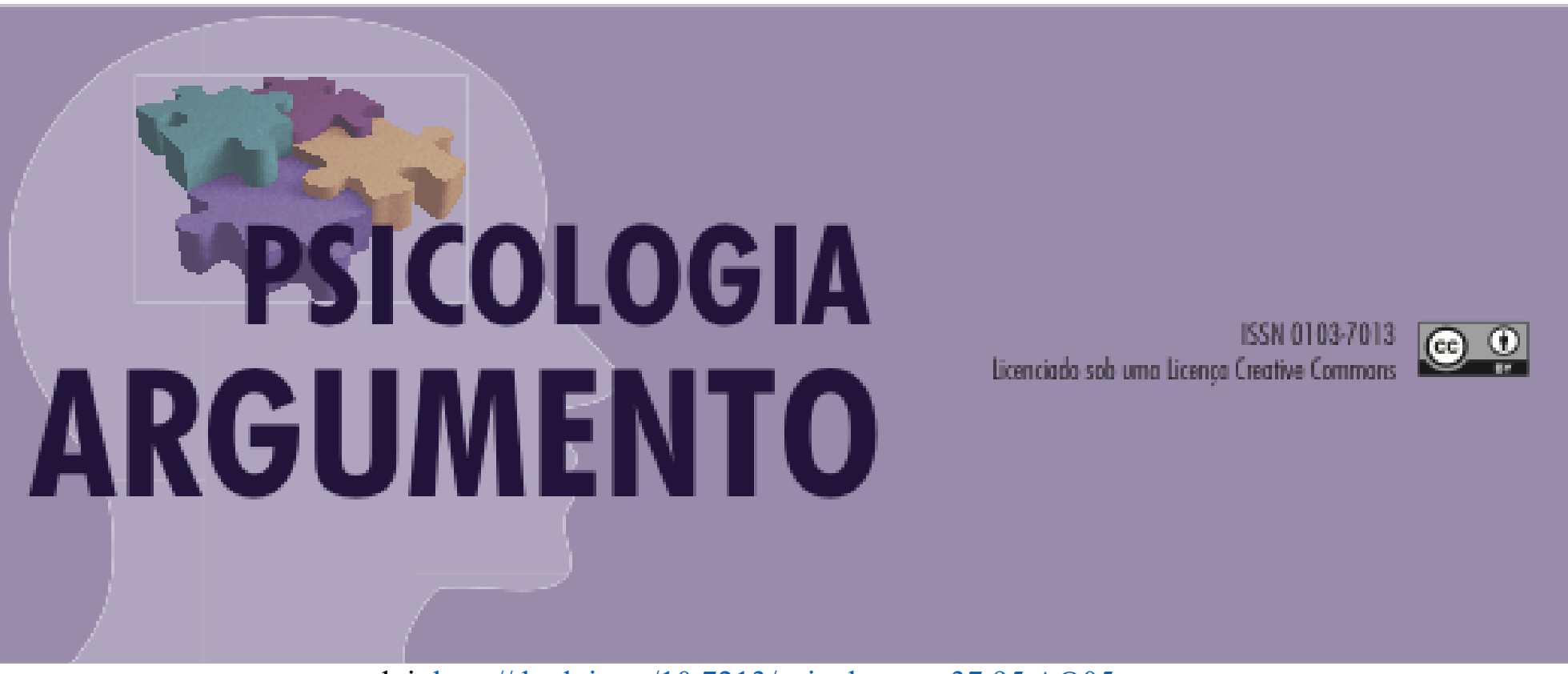

doi: http://dx.doi.org/10.7213/psicolargum.37.95.AO05

\title{
Estratégias de gestão de sala de aula utilizadas pelas professoras da educação infantil
}

Classroom management strategies used by preschool teachers

Estrategias de gestión del aula utilizadas por las profesoras de la educación infantil

\author{
Gisele Regina Stasiak \\ Orcid: http://orcid.org/0000-0002-8298-8272 \\ Instituto de Ensino Superior Sant'Ana. Email: giselestasiak@yahoo.com.br \\ Lidia Natalia Dobrianskyj Weber \\ Orcid: http://orcid.org/0000-0002-2217-447 \\ Universidade Federal do Paraná \\ Ana Rubia Alves Santos Carraro \\ Orcid: https://orcid.org/0000-0002-0445-8786 \\ Instituto de Ensino Superior Sant'Ana \\ Viviane Ribeiro Nunes \\ Orcid: https://orcid.org/0000-0002-4976-3805 \\ Instituto de Ensino Superior Sant'Ana
}

\section{Resumo}

Investigou-se, por meio da avaliação de observadores, as estratégias de gestão de sala de aula utilizadas por professoras da educação infantil. 20 professoras da educação infantil, com idade entre 22 e 46 participaram da pesquisa. O instrumento utilizado foi o Inventário de Boas Práticas (Webster-Stratton) e os dados coletados foram sistematizados utilizando-se o software SPSS (Statistical Package for the Social Sciences, versão 21). Verificou-se, de maneira geral, que as professoras utilizavam pouco as estratégias de gestão de sala de aula em seu cotidiano. Esse estudo 
exploratório trouxe elementos descritivos fundamentais para que propostas de formação e desenvolvimento de professores e de melhoria de suas habilidades educativas sejam inseridas preferencialmente nas salas de aula e que abranjam o cotidiano docente, seus saberes, vivências e desafios.

Palavras-chave: Educação infantil. Formação para professores. Estratégias de gestão de sala de aula.

\begin{abstract}
By means of observer assessment, this study sought to investigate classroom management strategies used by preschool teachers. 20 female preschool teachers took part in the study, aged between 22 and 46 years old. The instrument used was the Good Practices Inventory (WebsterStratton) and the data collected was systematized using SPSS (Statistical Package for the Social Sciences, version 21). In general it was found that the teachers made little use of classroom management strategies in their everyday work. This exploratory study has brought fundamental descriptive elements for teacher capacity-building, development and improvement of their educational skills proposals to be included preferably in the classroom, covering teachers' everyday activities, knowledge, experiences and challenges.
\end{abstract}

Keywords: Preschool education; Teacher training; Classroom management strategies.

Resumen: Se investigó por medio de la evaluación de observadores, las estrategias de gestión del aula utilizadas por profesoras de la educación infantil. 20 profesoras de educación infantil, con edad entre 22 y 46 años participaron de la encuesta. El instrumento utilizado fue el Inventario de Buenas Prácticas (Webster-Stratton) y los datos recopilados fueron sistematizados utilizando el software SPSS (Paquete Estadístico para Ciencias Sociales, versión 21). Se verificó, de manera general, que las profesoras utilizaban poco las estrategias de gestión de clase en su cotidiano. Ese estudio exploratorio ha aportado elementos descriptivos fundamentales para que las propuestas de formación y desenvolvimiento de profesores y de mejoría de sus habilidades educativas se inserten preferentemente en las clases y que abarquen el cotidiano docente, sus saberes, vivencias y desafios.

Palabras clave: Educación infantil. Formación para profesores. Estrategias de gestión en clase.

\title{
Introdução
}

Percebe-se que, no Brasil, a vida escolar de crianças tem se iniciado cada vez mais cedo. A literatura aponta diversos fatores para essa ocorrência como, por exemplo, falta de suporte familiar para compartilhar cuidados diários, limitações financeiras, famílias monoparentais, fortalecimento da crença sobre a importância de socialização, mas, principalmente, segundo Becker (2008), as ocupações profissionais das mulheres. Porém, sabe-se que não é fácil para os responsáveis/pais deixarem seu bebê ou sua criança pequena aos cuidados de outra pessoa. 
A família deseja que alguém carinhoso, afetivo, empático, paciencioso e dedicado dispense todo o cuidado com seu(sua) filho(a) (Brazelton, 2013). Historicamente, a educação infantil no Brasil esteve relacionada com a assistência, proteção, amparo e guarda de crianças, sendo focada exclusivamente em ações de cuidados instrumentais (por exemplo, dar banho, alimentar, trocar fraldas etc.) (Garcia, 2012). Gradativamente, a palavra guarda foi recebendo novos significados, sendo substituída pelo verbo cuidar, adicionando-se à palavra educar. Dessa forma, segunda a autora, cuidar e educar designam as funções da creche e da pré-escola. Porém, foi apenas após os anos de 1980 que essa visão da educação infantil foi vista de maneira mais clara, tendo fortalecido o projeto educativo que contempla a infância como um momento de grande riqueza para a construção dos conhecimentos e de potencialidades emocionais, sociais, intelectuais, físicas, éticas, afetivas etc. (Tomaz, 2012).

Segundo Campos (1997), a educação de crianças pequenas é uma das áreas educacionais mais promissoras em retornar à sociedade os recursos nela investidos. A educação infantil é vista como um dever do Estado, direito da criança e opção da família. Assim, é relevante analisar e refletir as condições nas quais os professores da educação infantil estão inseridos e que podem influenciar o atingimento dessa finalidade (Kramer, 2006), pois os pais e a sociedade esperam que a escola promova o desenvolvimento social, cognitivo e afetivo de suas crianças.

Portanto, além da família, a escola e seus profissionais - especialmente, os professores - precisam ter estratégias adequadas para utilizarem a fim de se sentirem seguros em suas atuações profissionais e criarem um ambiente propício ao bom desempenho escolar e ao desenvolvimento infantil de suas crianças. É fato que não são todos os comportamentos dos professores que promovem o desenvolvimento de competências e habilidades necessárias ao funcionamento global da criança. Nesse sentido, a construção de uma interação professor-aluno positiva tem sido o principal caminho apontado pela literatura como sendo a base em que a prática pedagógica do professor deve se pautar com o propósito de promover o sucesso acadêmico e o desenvolvimento social e prevenir problemas de comportamentos de seus alunos (Oliver, Wehby \& Reschly, 2011; Pianta, 2011; Vale, 2011).

Desde o primeiro dia da escola, as crianças da educação infantil devem confiar que terão suas relações com o professor em sala de aula baseadas em suporte e compreensão dia após dia (Hamre \& Pianta, 2001, 2006). Segundo esses autores, uma 
relação positiva e de proximidade permite que as crianças gostem da escola, relacionemse adequadamente com seus colegas, sintam-se capazes de se envolver em brincadeiras e realizem suas atividades de forma autônoma, pois sabem que ao se depararem com algumas dificuldades terão seus professores que dão suporte e respondem ao seu problema.

Alguns estudos envolvendo crianças, de aproximadamente quatro anos, indicam que uma relação professor-aluno positiva e de proximidade relaciona-se com melhores rendimentos acadêmicos em leitura, escrita e matemática (Burchinal et al., 2012; Burchinal et al., 2002; Howes et al., 2008). Para Webster-Stratton (2008), a relação professor-aluno se deve fundamentar na confiabilidade, validação, aceitação e encorajamento dos sentimentos e fortalecimento da autoconfiança da criança.

Bolsoni-Silva (2003) relata que interferir em determinadas situações comportamentais dos alunos não é suficiente; desse modo, o professor necessita utilizar estratégias para desenvolver habilidades sociais nas crianças. Del Prette e Del Prette (2008) apontam para um sistema de habilidades sociais educativas do professor, que é composto por quatro categorias de comportamento: (1) estabelecer contextos interativos potencialmente educativos (reorganizar o ambiente de maneira que os alunos possam se sentar em duplas ou grupos, inserir recursos audiovisuais, jogos interativos, utilizar materiais pedagógicos com diferentes texturas e cores, mediar interações incentivando os alunos à comunicação e ao convívio entre pares etc.); (2) transmitir ou expor conteúdos sobre habilidades sociais (realizar aula dialogada sobre as habilidades sociais primordiais para relacionamentos interpessoais satisfatórios e produtivos, destacar modelos de comportamento adequados mostrando suas consequências prováveis ou imediatas, elogiar comportamentos desejáveis feitos por outros colegas etc.); (3) estabelecer limites e disciplina (determinar de maneira clara e positiva as normas e regras a serem cumpridas, descrever verbalmente comportamentos adequados, identificar comportamentos indesejáveis etc.); (4) monitorar positivamente (estimular por meio de comportamentos positivos de modo a encorajar a criança, expressar concordância ou discordância levando o aluno a uma autoavaliação, reconstruir o interesse do aluno por intermédio de feedback positivo etc.).

Batista e Weber $(2012,2015)$, baseando-se nos estilos parentais, analisaram os estilos de liderança dos professores e constataram que o estilo autoritativo, ou seja, aquele professor que ao mesmo tempo estabelece regras e limites e tem um comportamento 
permeado de afetividade, considerando as características peculiares de cada fase da criança, é o estilo que tende a se apresentar como fator de proteção ao desenvolvimento da criança. Em outras palavras, January, Casey e Paulson (2011) apontam que, para alcançar resultados positivos, é preciso que o educador possua capacidades, competências e agilidade em gestão de sala de aula; assim o profissional estará contribuindo no processo de formação acadêmica, crescimento e desenvolvimento psicossocial da criança.

Entretanto, torna-se fundamental salientar que muitas vezes, em diferentes escolas e níveis de ensino, essas condições positivas da interação professor-aluno não se fazem presentes e se relacionam a prejuízos acadêmicos e comportamentais para as crianças. Glidden (2015) verificou práticas coercitivas dos professores tanto em escolas públicas quanto em privadas. Para Sidman (2001, p. 17), a coerção define-se como “[...] o uso da punição e da ameaça de punição para conseguir que outros ajam como nós gostaríamos ou a nossa prática de recompensar pessoas deixando-as escapar de nossas punições ou ameaças".

Sabe-se que a coerção tem seu efeito em curto prazo, pois leva a pessoa a se comportar como esperamos. Todavia, emno longo prazo ela é infrutífera, pois não ensina o acerto e, sim, realça o erro (Sidman, 2001). Em sua pesquisa, Vale e Gaspar (2004) identificaram que as professoras da educação infantil percebem a utilização de estratégias inadequadas na interação com as crianças como, por exemplo, comentar em voz alta o comportamento indesejado da criança, apontar uma criança por comportamento incorreto, recorrer à força física etc. Stasiak (2010) verificou, em sua pesquisa com 39 crianças de aproximadamente seis anos de idade, que elas observaram comportamentos das professoras como, por exemplo, gritar, falar palavrões ou beliscão em sua interação com elas, sendo que essa situação teve relação com suas percepções de estresse. Weber et al. (2015) falam que a quantidade de alunos na classe é uma das origens do estresse para as docentes, sendo este um fator que pode dificultar a interação e a comunicabilidade entre docente e discente.

Para Regra (2004), outro comportamento de coerção ou de adversidade emitido pelo professor pode ser identificado quando ele enfatiza exclusivamente as dificuldades de aprendizagem ou comportamentais das crianças e ignora os acertos e potencialidades do seu aluno. Essa postura, na maior parte das vezes, leva à rotulação das crianças como imaturas, desinteressadas, preguiçosas, irresponsáveis etc., ocasionando uma polaridade severa na interação professor-aluno: isenção dos professores de suas responsabilidades 
pelo não ensino e a total responsabilidade da criança pela não aprendizagem (Pereira, Marinotti \& Luna, 2004; Skinner, 1972). Bolsoni-Silva (2003), Bolsoni-Silva, Del Prette e Oishi (2003) e Bolsoni-Silva et al. (2006) trazem a informação de que as docentes empregam com mais constância as estratégias de estabelecimento de limites quando o número de crianças do gênero masculino é predominante; essa correspondência pode estar associada ao fato de que o gênero tem uma tendência maior a questões de problemas de comportamento externalizados.

É fato, portanto, que a coerção e a rotulação estreitam severamente as oportunidades de aprendizagem das crianças favorecendo que elas se comportem de maneira coerente com tais rotulações, diminuindo sua criatividade e flexibilidade comportamental, e fortalecendo seus comportamentos rígidos e estereotipados, ou seja, comportamentos opostos aos comportamentos necessários ao processo de aprendizagem (Vasconcelos, 2003; Viecili \& Medeiros, 2002).

Dessa forma, é inquestionável que o professor, por meio de uma interação positiva com seu aluno, pode funcionar como um fator de proteção, pois por esse caminho ele contribui para a minimização dos fatores de risco aos quais as crianças estão expostas, tornando-se o suporte necessário para que essa trajetória de risco seja modificada já nos primeiros anos de vida da criança (Pianta, 1998; Webster-Stratton, 2008). Sabe-se que uma pré-escola de qualidade, ou seja, uma experiência escolar composta por uma relação afetiva e responsiva por parte de seu professor tem o poder de igualar as condições de desempenho de crianças oriundas de famílias mais favorecidas e famílias em desvantagem social (Sylva et al., 2014).

Ao olhar para a interação professor-aluno positiva, percebe-se que outros conhecimentos do professor também são importantes para que o processo ensinoaprendizagem seja potencializado. Stasiak (2016) verificou que a idade e a experiência do professor são variáveis que contribuem para que ele utilize em sala de aula as estratégias de ensino de competências sociais e emocionais, como, por exemplo, tranquilidade, autoestima, cooperação etc.

$\mathrm{Na}$ literatura internacional, essa área recebem o nome de classroom management, ou seja, estudo de gestão de sala de aula, que se refere aos conhecimentos e estratégias mais diretivas e pontuais envolvendo a estrutura física do espaço, bem como a condução das atividades da sala de aula, conforme destacado por Stasiak (2016). Percebe-se que o campo da gestão de sala de aula vem sendo estudado desde as décadas iniciais do século 
XX (Brophy, 2011), trazendo contribuições relevantes à qualificação e ao desenvolvimento profissional do professor (Emmer \& Stough, 2001).

De acordo com a Associação Americana de Psicologia (American Psychological Association, 2010), o conceito de classroom management se refere ao uso de estratégias básicas de ensino utilizadas pelo professor a fim de promover melhores relações e aprendizado dos alunos em sala de aula como, por exemplo, alterar os lugares dos alunos, flexibilizar prazos e exigências para tarefas e lições, entre outros. Para Brophy (2011), a gestão de sala de aula se define como sendo as ações do professor focadas em criar e manter um ambiente propício de aprendizagem com o objetivo de alcançar sucesso em sua prática de ensino.

A organização da sala de aula é um componente importante na gestão de sala de aula pelo professor. Abbas, Othman e Rahman (2012) pesquisaram o espaço físico de 20 pré-escolas e identificaram que áreas de atividades bem definidas e um ambiente estruturado (ausência de paredes na sala, materiais diversos disponíveis, mobiliário apropriado à idade da criança) relacionaram-se positivamente à emissão de comportamentos positivos de brincadeiras pelas crianças. Para Lane et al. (2011), o espaço físico da sala de aula deve contemplar: áreas de aprendizagem específicas; materiais armazenados em lugares específicos e identificados; trabalhos dos alunos expostos; iluminação adequada; painel, cartaz ou quadro de registro das definições elaboradas diariamente pelo grupo; área reservada para encaminhar especificamente alguma criança que tenha tido algum comportamento inapropriado; carteiras e espaços seguros para circulação das crianças e visibilidade do educador etc.

Além da organização física da sala de aula, o professor precisa ocupar-se do planejamento de atividades. Alguns princípios podem subsidiar um planejamento de ensino pelo professor que respeite a aprendizagem individual e o ritmo de cada aluno nas atividades: (1) manter o aluno constantemente em atividade a fim de acompanhar seu desempenho; (2) ressaltar ao máximo as aproximações do aluno ao desempenho adequado, criando condições para que ele aprenda o que ainda não sabe; (3) garantir que as atividades sejam compatíveis com o que ele já sabe e aumentar gradativamente a dificuldade delas evitando ao máximo consequências aversivas; (4) priorizar consequências que são inerentes à ação; e, por fim, (5) envolver o aluno ao máximo na avaliação de seu próprio desempenho (Pereira, Marinotti \& Luna, 2004). Quando o professor realizar a passagem de uma atividade a outra, é fundamental que ele encerre a 
atividade em curso e, só então, inicie a nova atividade utilizando sinalizadores a fim de garantir a atenção de seus alunos para que eles saibam como e para onde devem ir (Lane et al., 2011).

\section{Objetivos}

Pode-se dizer que o professor que se preocupa em favorecer uma aprendizagem acadêmica e um desenvolvimento global positivo e de sucesso às crianças precisa se comportar por meio de uma interação positiva e utilizar em sua sala de aula estratégias específicas. Buscando contribuir nessa direção teórica, a presente pesquisa avaliou as estratégias de gestão de sala de aula utilizadas por professoras da educação infantil. Essa pesquisa é uma investigação de caráter exploratório e o instrumento utilizado foi respondido por meio de observadores.

\section{Método}

\section{Participantes}

Participaram da pesquisa vinte professoras da educação infantil, sendo nove professoras de uma escola particular, quatro professoras de uma escola pública e sete de uma escola filantrópica de uma cidade do interior do estado do Paraná. As participantes tinham idade entre 22 e 46 anos (média de 31,68 anos e desvio padrão de 6,68), tendo em sala de aula aproximadamente vinte crianças ${ }^{1}$, entre 2 e 6 anos. Em relação ao estado civil das participantes, $25 \%$ eram solteiras e $75 \%$ casadas. Em relação à formação acadêmica, cinco participantes (25\%) apresentaram licenciatura em Pedagogia em andamento e quinze participantes (75\%) licenciatura em Pedagogia concluída sendo que nove professoras das quinze apresentaram especialização concluída. Em relação à renda salarial mensal, $25 \%$ das participantes apresentaram renda mensal de um salário mínimo nacional, $50 \%$ delas dois salários mínimos, $15 \%$ três salários mínimos, $5 \%$ quatro salários mínimos e 5\% acima de cinco salários mínimos.

\footnotetext{
${ }^{1}$ A partir desse momento do artigo, optou-se por utilizar a palavra "criança" e não "aluno" pela presente pesquisa se referir exclusivamente ao contexto da Educação Infantil.
} 


\section{Instrumento}

Inventário de boas práticas (Best Practices Inventory - BPI): esse inventário foi construído por Carolyn Webster-Stratton para o Projeto Incredible Years da Universidade de Washington e foi traduzido por Vale (2011). Esse instrumento foi adaptado linguística e semanticamente ao contexto cultural nacional por Stasiak (2016). O instrumento objetiva identificar quais são as estratégias que a professora utiliza na gestão da sua sala de aula e dos comportamentos das crianças por meio de observadores. São 80 questões, sendo os itens avaliados por meio do modelo Likert de cinco pontos (nunca, quase nunca, às vezes, quase sempre e sempre) e divididos em nove subescalas: A) Organização da sala, com sete questões (por exemplo, "a sala de aula permite que todas as crianças estejam visíveis a professora"); B) Planejamento e transições, com doze questões (por exemplo, "o planejamento diário alterna atividades mais agitadas e outras mais calmas"); C) Atividades, com treze questões (por exemplo, "existe um espaço físico demarcado para reunião da turma toda"); D) Planos de comportamento, com seis questões como, por exemplo, "a professora se assegura que todas as crianças tem uma forma de se comunicarem apropriadamente e funcionalmente"); E) Ensino individualizado, com nove questões (por exemplo, "as atividades são ensinadas da mais simples e concreta às mais complexas e abstratas"); F) Práticas emocionais, com doze questões (por exemplo, "a professora utiliza situações reais para praticar a resolução de problemas iniciando por definir o problema e as emoções envolvidas"); G) Relacionamento/comunicação, com oito questões (por exemplo, "a professora fala calmamente com as crianças"); H) Disciplina, com sete questões (por exemplo, "as consequências do cumprimento ou não das regras são claras"); I) Envolvimento parental, com seis questões (por exemplo, "a professora convida os pais para encontros/reuniões").

\section{Procedimentos}

Considerações éticas: a coleta de dados foi realizada após a aprovação da presente pesquisa junto ao Comitê de Ética em Saúde da Universidade Federal do Paraná, sob o número 38579214.4.0000.0102. O Termo de Consentimento Livre e Esclarecido (TCLE) foi assinado por todos os participantes do estudo. Cada participante teve seu comportamento observado por duas horas não consecutivas sendo que cada observação deveria ter no mínimo 40 minutos e acontecer em diferentes momentos da rotina escolar. 
Após a conclusão, os participantes receberam retorno dos resultados da pesquisa em forma de workshop.

Análise de dados

Os dados coletados foram sistematizados utilizando-se o software SPSS (Statistical Package for the Social Sciences, versão 21). As análises foram geradas por meio de medidas descritivas (média, porcentagem e desvio padrão etc.) e foram obtidas as médias das escalas e subescalas avaliadas. Em relação aos testes estatísticos, foram utilizados testes não paramétricos (correlação de Spearman). Para avaliar a consistência interna dos instrumentos, aplicou-se o coeficiente Alpha de Cronbach tanto para o instrumento no todo quanto para suas subescalas.

\section{Resultados e Discussão}

Destaca-se em primeiro lugar que as 20 professoras foram observadas por meio do Inventário de boas práticas $(B P I)$ por duas duplas de observadores, que foram selecionadas estatisticamente entre si por meio do coeficiente de Kappa de Cohen, cujas observações apresentaram grau substancial de correspondência para os parâmetros estabelecidos por Landis e Koch (1977) sendo dupla A $(k=0,65 ; \mathrm{p}=0,00)$ e dupla B $(\mathrm{k}=0,72 ; \mathrm{p}=0,00)$.

Em relação às participantes, a caracterização da amostra foi analisada por meio da Tabela 1. Todavia, percebe-se que alguns dados (idade da professora B, faixa etária dos alunos da professora $F$ e gênero dos alunos das professoras $J, Q$ e $S$ ) não foram, infelizmente, disponibilizados pelas participantes.

A Tabela $1^{2}$ demonstra que a idade média dos professores foi de 31,68 anos (desvio padrão de 6,68) e o tempo de atuação em sala de aula foi de 8,80 anos (desvio padrão de 5,34). January, Casey e Paulson (2011) apontam que os profissionais que atuam há mais tempo demonstram maior probabilidade de desenvolver melhores estratégias no ensino utilizando suas experiências adquiridas no exercício da profissão. Stasiak (2016) analisou que professores mais experientes e com maior tempo de exercício da profissão utilizam técnicas e procedimentos proativos com maior frequência, obtendo resultados satisfatórios para aprendizagem de suas crianças. Sendo assim, compreendem claramente

\footnotetext{
${ }^{2}$ Análises realizadas sem os dados faltantes.
} 
os efeitos positivos em suas estratégias, expressando orientações diretivas, positivas e claras, utilizando-se de meios assertivos para solucionar problemas, ter o controle da raiva e auxiliar as crianças na identificação e compreensão das emoções. Segundo a mesma autora, o docente utiliza, em sala de aula, meios disciplinares elaborados estrategicamente e sinaliza suas crianças sobre o momento em que se dará a mudança de atividade, ou seja, o professor utiliza estratégias de ensino para obter respostas desejadas. Em outras palavras, o profissional apresenta um repertório apropriado e utiliza uma gama de estratégias que antecipam situações, assegurando comportamentos apropriados e propícios para prevenir condutas inadequadas em gestão de sala de aula (Vale, 2011).

Tabela 1 - Caracterização da amostra do estudo

\begin{tabular}{|c|c|c|c|c|c|c|c|}
\hline \multirow{2}{*}{ 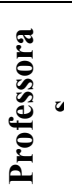 } & \multirow{2}{*}{$\begin{array}{l}\text { Idade } \\
\text { (anos) }\end{array}$} & \multirow{2}{*}{$\begin{array}{c}\text { Tempo } \\
\text { atuação } \\
\text { (anos) }\end{array}$} & \multirow{2}{*}{$\begin{array}{l}\text { Formação } \\
\text { acadêmica }\end{array}$} & \multicolumn{2}{|l|}{$\begin{array}{c}\text { Faixa etária } \\
\text { alunos (anos) }\end{array}$} & \multicolumn{2}{|c|}{ Número de alunos } \\
\hline & & & & Média & Total & $\begin{array}{c}\text { Gênero } \\
\text { masculino }\end{array}$ & $\begin{array}{c}\text { Gênero } \\
\text { feminino }\end{array}$ \\
\hline A & 30 & 5 & $\begin{array}{c}\text { Neuro } \\
\text { Psicopedagogia }^{(\mathrm{c})}\end{array}$ & $3-4$ & 17 & $10(58,8 \%)$ & $7(41,2 \%)$ \\
\hline B & - & 8 & $\begin{array}{l}\text { Educação } \\
\text { Especial }^{(\mathrm{c})}\end{array}$ & $5-6$ & 24 & $16(66,7 \%)$ & $8(33,3 \%)$ \\
\hline $\mathrm{C}$ & 32 & 13 & Pedagogia $^{(a)}$ & $4-5$ & 20 & $11(55 \%)$ & $9(45 \%)$ \\
\hline $\mathrm{D}$ & 24 & 2 & $\begin{array}{l}\text { Psicopedagogia } \\
\text { Clínica e } \\
\text { Institucional }^{(\mathrm{c})}\end{array}$ & $2-3$ & 17 & $8(47 \%)$ & $9(53 \%)$ \\
\hline $\mathrm{E}$ & 45 & 10 & Educação Infantil $^{(\mathrm{c})}$ & $3-4$ & 16 & $8(50 \%)$ & $8(50 \%)$ \\
\hline $\mathrm{F}$ & 37 & 14 & Pedagogia $^{(\mathrm{b})}$ & Outra & 16 & $9(56,3 \%)$ & $7(43,7 \%)$ \\
\hline G & 33 & 10 & Pedagogia $^{(b)}$ & $3-4$ & 22 & $10(45,5 \%)$ & $12(54,5 \%)$ \\
\hline $\mathrm{H}$ & 35 & 16 & $\begin{array}{l}\text { Psicopedagogia, } \\
\text { Arte Terapia }{ }^{\text {(c) }}\end{array}$ & $4-5$ & 22 & $12(54,5 \%)$ & $10(45,5 \%)$ \\
\hline I & 46 & 20 & Pedagogia $^{(b)}$ & $4-5$ & 20 & $16(80 \%)$ & $4(20 \%)$ \\
\hline $\mathrm{J}$ & 28 & 3 & Pedagogia $^{(a)}$ & $2-3$ & 22 & - & - \\
\hline $\mathrm{K}$ & 24 & 3 & Pedagogia ${ }^{(b)}$ & $4-5$ & 21 & $11(52,4 \%)$ & $10(47,6 \%)$ \\
\hline $\mathrm{L}$ & 30 & 8 & $\begin{array}{c}\text { Neuro } \\
\text { Psicopedagogia }^{(\mathrm{c})}\end{array}$ & $3-4$ & 19 & $8(42,1 \%)$ & $11(57,9 \%)$ \\
\hline M & 39 & 15 & $\begin{array}{c}\text { Lingua } \\
\text { Portuguesa }^{(\mathrm{c})}\end{array}$ & $4-5$ & 20 & $10(50 \%)$ & $10(50 \%)$ \\
\hline $\mathrm{N}$ & 25 & 5 & Pedagogia $^{(b)}$ & $3-4$ & 20 & $10(50 \%)$ & $10(50 \%)$ \\
\hline $\mathrm{O}$ & 32 & 13 & Gestão Escolar $^{(\mathrm{c})}$ & $5-6$ & 22 & $11(50 \%)$ & $11(50 \%)$ \\
\hline $\mathrm{P}$ & 27 & 2 & Pedagogia $^{(a)}$ & $2-3$ & 18 & $10(55,6 \%)$ & $8(44,4 \%)$ \\
\hline Q & 27 & 5 & Pedagogia $^{(a)}$ & $4-5$ & 22 & - & - \\
\hline $\mathrm{R}$ & 33 & 5 & Pedagogia $^{(b)}$ & $3-4$ & 20 & $9(45 \%)$ & $11(55 \%)$ \\
\hline $\mathrm{S}$ & 22 & 5 & Pedagogia ${ }^{(a)}$ & $3-4$ & 22 & - & - \\
\hline $\mathrm{T}$ & 33 & 14 & $\begin{array}{l}\text { Educação Especial } \\
\text { e Inclusão (c) }\end{array}$ & $3-4$ & 16 & $9(56,3 \%)$ & $7(43,7 \%)$ \\
\hline
\end{tabular}

Notas: (a) Curso em andamento; (b) Curso concluído; (c) Especialização Fonte: Elaborada pelas autoras, 2017.

Em relação à formação acadêmica, nove professoras possuíam o curso de especialização, seis com formação acadêmica concluída e cinco professores estavam com seus cursos superiores em andamento. Ainda é possível destacar que as professoras 
possuíam em média 19,80 crianças em sala de aula (desvio padrão de 2,42), os quais possuíam idades entre dois e seis anos, sendo 178 (53,94\%) do gênero masculino e 152 $(46,06 \%)$ do gênero feminino. Weber et al. (2015) refletem sobre a quantidade de discentes em sala de aula, sendo este um fator relevante na interação positiva entre professor e criança, podendo esta ser uma variável que poderá contribuir para o esgotamento físico e emocional do professor. A literatura aponta inclusive que o profissional faz uso constante de técnicas e procedimentos para assegurar limites quando o número de crianças do gênero masculino é superior ao feminino, pois os meninos tendem a manifestar maiores dificuldades de comportamentos (Bolsoni-Silva, 2003; Bolsoni-Silva, Del Prette \& Oishi, 2003; Bolsoni-Silva et al., 2006).

Quando comparadas as estratégias que as professoras de escolas públicas, privadas e filantrópicas utilizam na gestão da sua sala de aula e dos comportamentos das crianças, não foi encontrada diferença significativa $\left(\chi^{2}=32,78 ; \mathrm{p}>0,05\right)$. Adicionalmente, foram calculadas as médias simples geral das estratégias utilizadas por cada uma das professoras e observou-se que a menor média $(2,02)$ foi de uma professora de escola privada e a maior $(3,93)$ foi de uma de escola filantrópica. Ao calcular-se a média simples geral das estratégias utilizadas pelas professoras por escola encontrouse o resultado de que a escola pública obteve a maior média $(2,97)$, seguida pela escola filantrópica $(2,90)$ e, por fim, a escola privada $(2,71)$. Esses achados podem servir de maneira mais ampla a um dado reflexivo de que as professoras, mais especificamente, suas estratégias de gestão de sala de aula, quando correspondem à afetividade e responsividade, podem percorrer o caminho apontado por Sylva et al. (2014) de que a pré-escola, dessa forma, pode servir como um contexto igualitário de diferenças sociais.

O instrumento Inventário de Boas Práticas (IBP) teve sua consistência interna verificada por meio do coeficiente Alfa de Cronbach, o qual apresenta o valor geral de 0,97 e os seguintes valores para suas subescalas: "organização da sala" $(\alpha=.81)$, "planejamento e transições" ( $\alpha=.74)$, "atividades" ( $\alpha=.87)$, "planos de comportamentos" $(\alpha=.83)$, “ensino individualizado" $(\alpha=.85)$, "práticas emocionais" $(\alpha=.90)$, "relacionamento/comunicação" ( $\alpha=.86)$, "disciplina" $(\alpha=.72)$ e, por fim, "envolvimento parental" $(\alpha=.71)$. De maneira geral, os índices de confiabilidade encontrados no presente estudo superaram os achados por Vale (2011) e Stasiak (2016) em suas pesquisas e conclui-se que o instrumento demonstrou alto índice de confiabilidade. 
Em relação aos escores médios às médias das subescalas do instrumento $B P I$, pode-se observar uma média geral de $3,10(\mathrm{dp}=0,65)$. Em ordem decrescente, a subescala "ensino individualizado" apresentou a maior média $(3,70 ; \mathrm{dp}=0,84)$, seguida das subescalas "envolvimento parental" $(3,57 ; d p=0,73)$, "atividades" $(3,41 ; d p=0,74)$, "planos de comportamento" $(3,26 ; \mathrm{dp}=0,89)$, “organização da sala" e "relacionamento/comunicação" $(3,13 ; \mathrm{dp}=0,98)$, "planejamento e transições" $(2,92$; $\mathrm{dp}=0,60)$, “disciplina" $(2,66 ; \mathrm{dp}=0,80) \mathrm{e}$ "práticas emocionais" $(2,42 ; \mathrm{dp}=0,82)$. De forma geral, o último resultado chama muito a atenção, pois a categoria de respostas "quase nunca" foi a mais freqüente em relação ao fato de a professora desenvolver práticas com suas crianças em relação ao comportamento social e emocional. Essa tarefa é de suma importância, pois se sabe que o professor indubitavelmente é capaz de promover o desenvolvimento social e prevenir problemas de comportamento de suas crianças (Oliver, Wehby \& Reschly, 2011; Pianta, 2011; Vale, 2011).

Foram verificadas as correlações (teste de Spearman) entre as subescalas do instrumento IBP, sendo que os resultados apontaram forte correlação entre grande parte das subescalas desse instrumento. Para tanto, destacam-se as correlações mais fortes e significativas encontradas: "ensino individualizado" com "planos de comportamento" ( $\rho=0,88 ; p<0,001)$ e com "práticas emocionais" $(\rho=0,84 ; p<0,001)$; "atividades" com "planejamento e transições" $(\rho=0,83 ; p<0,001)$ e com "relacionamento/comunicação" $(\rho=0,82 ; p<0,001)$; "relacionamento/comunicação" com "práticas emocionais" $(\rho=0,80$; $\mathrm{p}<0,001$ ). Esses resultados apontam para direções como: (1) quando as professoras investem em estratégias de "ensino individualizado", ou seja, elas incluem em sua prática ações que considerem as diferenças e necessidades específicas de suas crianças, elas favorecem suas próprias estratégias para lidar com os comportamentos inadequados e adequados das crianças, bem como para promover as habilidades sociais de suas crianças. Dessa forma, pode-se pensar que as professoras não estariam interagindo por coerção com suas crianças, ou seja, não estariam focando nas dificuldades de aprendizagem ou comportamentais das crianças e, sim, focando em seus acertos e potencialidades (Regra, 2004); (2) quando as professoras estabelecem suas atividades em sala de aula de forma individual e coletiva, dando orientações, ênfase e acompanhando os comportamentos das crianças, elas demonstram maior planejamento e relacionamento afetivo com eles; (3) por fim, percebe-se que um relacionamento baseado em comunicação positiva e assertiva da professora com suas crianças e expressão de afetividade favorece o desenvolvimento de 
comportamentos pró-sociais das crianças. De maneira geral, os dados sugerem que quando a professora se utiliza dessas estratégias para gerir sua sala de aula, ela está utilizando ações direcionadas a criar e manter um clima positivo em sala de aula, ou seja, propício de aprendizagem (Brophy, 2011).

Realizou-se o cálculo das médias dos escores assinalados pelas professoras dos itens de cada subescala, conforme se apresenta a seguir. $O$ item de menor média $(1,15$; $d p=0,67)$ da subescala "organização da sala" foi "existem pistas visuais que permitem à criança saber quando uma área de aprendizagem ou atividade não está disponível (p. ex.: sinal de Pare, área coberta)" e o de maior média $(4,37 ; \mathrm{dp}=0,82)$ foi "a sala de aula permite que todas as crianças estejam visíveis à professora (p. ex.: estantes ou paredes mais baixas do que as crianças)". A subescala "planejamento e transições" apresentou o item "existe um sistema (p. ex.: quadro, tabela, cartões) que permite às crianças a escolha de quais áreas de aprendizagem querem utilizar" com menor média $(1,07 ; \mathrm{dp}=0,24)$ e o item “existe um planejamento diário de atividades sendo previsível e flexível ao mesmo tempo" com maior média $(4,07 ; \mathrm{d} p=0,63)$. Observa-se, nesse sentido, a necessidade das professoras em aumentar em sua sala de aula o apontamento realizado por Lane et al. (2011), ou seja, a importância de existirem fatores que favoreçam a evolução das atividades propostas pelo professor e que proporcionem às crianças possibilidade de escolher entre tarefas variadas.

A subescala "atividades" demonstrou o item "diariamente a professora planeja atividades de cooperação entre as crianças" com menor média $(2,67 ; \mathrm{dp}=1,59)$ e "existe um espaço físico demarcado para a reunião da turma toda (p. ex.: tapete)" com maior média $(4,6 ; d p=1,09)$. O item com menor média da subescala "planos de comportamentos" foi "a professora utiliza de forma apropriada e com moderação estratégias como 'time-out' (tempo de pausa), ignorar ou redirecionar o comportamento inapropriado" $(2,82 ; \mathrm{dp}=1,01)$ e o com maior média foi "todo material, referente aos planos de comportamento existentes, é guardado para ser utilizado na avaliação e revisão de ações" $(3,65 ; \mathrm{dp}=1,55)$. Pode-se dizer que as professoras mostram menor investimento em estratégias que promovam o relacionamento interpessoal satisfatório entre as crianças e menor uso de estratégias adequadas para lidarem com comportamentos indesejados das crianças.

A subescala "ensino individualizado" apresentou o seguinte item com menor média: "quando necessário, a professora adapta sua metodologia de ensino à necessidade 
de cada criança (p. ex.: visual, auditiva, motora)" $(2,80 ; \mathrm{dp}=1,80)$ e o de maior média "os materiais são adaptados às crianças de acordo com a idade (p. ex.: lápis, espessura do papel, tapetes de estabilização, velcros para fixar materiais)" (4,52; dp=0,81). O item que apresentou menor média da subescala "práticas emocionais" foi "a professora promove a regulação emocional das crianças, a fim de favorecer a interação social positiva na sala, expondo fotos das crianças e trabalhando nas soluções" $(1,10 ; \mathrm{dp}=0,26)$ e o de maior média foi "a professora, o ambiente e as atividades da sala de aula promovem a identificação e expressão pela criança das suas próprias emoções e as dos outros; a professora demonstra perceber como as crianças se sentem por meio da validação e aceitação dos sentimentos, colocando-se como modelo, nomeando sentimentos, os tons de voz ou gestos expressados pelas crianças" $(2,87 ; \mathrm{dp}=1,17)$. Pode-se afirmar que o uso das estratégias citadas assegura que as professoras estariam interagindo com suas crianças promovendo seu desenvolvimento global (Pereira, Marinotti \& Luna, 2004).

A subescala "relacionamento/comunicação" apresentou, respectivamente, os itens com menor e maior médias: "a professora permite que as atividades livres sejam de iniciativa da criança" $(1,80 ; \mathrm{dp}=1,25)$ e "a professora fala calmamente com as crianças" $(3,97 ; \mathrm{dp}=1,27)$. O item com menor média da subescala "disciplina" foi "a professora possibilita que as crianças façam escolhas" $(1,92 ; \mathrm{dp}=1,16)$ e os dois itens com maiores médias foram "a professora ignora comportamentos inadequados das crianças que são apenas para chamar a atenção" $(2,97 ; \mathrm{dp}=0,89)$ e "a professora utiliza comportamentos adequados de colegas para que as outras crianças se comportem da mesma forma" $(2,97$; $\mathrm{dp}=1,00$ ). Por fim, a subescala "envolvimento parental" apresentou o item "a professora cria oportunidades para os pais observarem a equipe pedagógica e participarem de suas atividades em sala de aula" com menor média $(3,12 ; \mathrm{dp}=1,56)$ e o item "a professora estabelece um sistema de comunicação regular com os pais (p. ex.: telefonemas, cartas, agenda, mensagens positivas, quadro de recados)" com maior média $(4,77 ; \mathrm{dp}=0,41)$.

Conclui-se, por meio desse estudo exploratório, que, de maneira geral, o uso de estratégias de gestão de sala de aula e do comportamento da criança de forma adequada e positiva pelas participantes pode ser aprimorado, pois os escores médios revelam que a frequência de utilização ainda é baixa. Assim, a análise das correlações fortes e significativas encontradas, sugere que o corpo docente da educação infantil privilegie o “ensino individualizado", os "planos de comportamento", as "práticas emocionais", o "relacionamento/comunicação", as "atividades" e o "planejamento e transições" em seu 
dia a dia de sala de aula. Para isso, é importante que o professor busque, por exemplo, promover a cooperação entre pares, a autorregulação emocional das crianças, estimulando positiva e afetivamente suas escolhas, construindo pistas visuais para seus comportamentos esperados e atividades a serem realizadas etc.

\section{Considerações finais}

A tarefa do professor é complexa e exigente, pois envolve a necessidade de o professor se atentar individual e coletivamente às suas crianças, além de manter uma interação positiva e gestão de sala de aula com estratégias específicas ao desenvolvimento escolar e global de suas crianças. Os resultados apontam para uma direção importante revelando que as professoras podem aumentar a frequência do uso de estratégias positivas de gestão de sala de aula em seu cotidiano escolar, favorecendo, por exemplo: a utilização de pistas visuais sobre áreas de aprendizagem, comportamentos esperados e atividades a serem realizadas; atividades e interações entre pares voltadas à cooperação; utilização de estratégias adequadas para manejar comportamentos inadequados das crianças, permitindo que as crianças realizem escolhas etc. Por fim, destaca-se uma reflexão importante incitada pelos resultados em relação aos escores médios das habilidades de gestão das professoras, de que as escolas privadas e públicas podem apresentar condições de equiparar-se em termos de estratégias de gestão de sala de aula de seus professores. De maneira geral, espera-se que esse estudo exploratório possa auxiliar o campo de formação de professores, profissão tão nobre e admirável, em relação às suas habilidades educativas, pois ainda é um caminho a ser potencializado na literatura e em programas de intervenção voltados ao contexto escolar.

\section{Referências}

Abbas, M. Y., Othman, M., \& Rahman, P. Z. M. A. (2012). Pre-school classroom environment: significant upon children's' play behaviour? Social and Behavioural Sciences, 49, 47-65.

American Psychological Association (APA) (2010). Dicionário de Psicologia APA. Porto Alegre, RS: Artmed. 
Batista, A. P., \& Weber, L. N. D. (2012). Estilos de liderança de professores: aplicando o modelo de estilos parentais. Psicologia Escolar e Educacional, 16(2), 299-307.

Batista, A. P., \& Weber, L. N. D. (2015). Professores e estilos de liderança: manual para identificá-los e modelo teórico para compreendê-los. Curitiba: Juruá.

Becker, F. R. (2008). Educação Infantil no Brasil: a perspectiva do acesso e do financiamento. Revista Iberoamericana de Educación, 47, 141-155.

Bolsoni-Silva, A. T. (2003). Habilidades sociais educativas, variáveis contextuais e problemas de comportamento: comparando pais e mães de pré-escolares (Tese de doutorado). Universidade de São Paulo, São Paulo, SP.

Bolsoni-Silva, A. T., Del Prette, A., \& Oishi, J. (2003). Habilidades sociais de pais e problemas de comportamento de filhos. Argumento, 9, 11-29.

Bolsoni-Silva, A. T., Marturano, E. M., Pereira, V. A., \& Manfrinato, J. W. S. (2006). Habilidades Sociais e Problemas de Comportamento de Pré-Escolares: comparando Avaliações de Mães e de Professoras. Psicologia: Reflexão e Crítica, 19(3), 460-469.

Brazelton, T. B. (2013). O grande livro da criança: o desenvolvimento emocional e do comportamento durante os primeiros anos (M. F. Peixoto, trad.). Barcarena, Portugal: Presença.

Brophy, J. (2011). History of research on classroom management. In C. M. Evertson, \& C. S. Weinstein (Orgs.), Handbook of classroom management (pp. 17-43). New York, NY: Routledge.

Burchinal, M. R., Peisner-Feinberg, E., Pianta, R., \& Howes, C. (2002). Development of academic skills from preschool through second grade: family and classroom predictors of developmental trajectories. Journal of School Psychology, 40(5), 415-436

Burchinal, M., Field, S., López, M. L., Howes, C., \& Pianta, R. (2012). Instruction in Spanishin pre-kindergarten classrooms and child outcomes for English language learners. Early Childhood Research Quarterly, 27, 188-197.

Campos, M. M. (1997). Educação infantil: o debate e a pesquisa. Cadernos de Pesquisa, $101,113-127$.

Del Prette, Z. A. P., \& Del Prette, A. (2008). Um Sistema de categorias de habilidades sociais educativas. Paideia, 18 (41), 517-530. 
Emmer, E. T., \& Stough, L. M. (2001). Classroom management: a critical part of educational psychology, with implications for teacher education. Educational Psychologist, 36(2), 103-112.

Garcia, R. A. (2012). O lugar do cuidado na ação pedagógica com os bebês. In A. S. Coutinho, G. Day, \& V. Wiggers (Orgs.), Práticas pedagógicas na educação infantil: diálogos possíveis a partir da formação profissional (pp. 56-69). São Leopoldo, RS: Oikos.

Glidden, R. F. (2015). Práticas coercitivas docentes: relações com envolvimento, monitoria parental e comunicação pais e filhos. (Dissertação de mestrado). Universidade Federal do Paraná, Curitiba, PR.

Hamre, B. K., \& Pianta, R. C. (2001). Early teacher-child relationships and the trajectory of children's school outcomes through eighth grade. Child Development, 72 (2), 625638.

Hamre, B. K., \& Pianta, R. C. (2006). Student-teacher relationships. In G. G. Bear \& K. M. Minke (Eds.) Children's needs III: development, prevention and intervention, (pp. 49-60). Bethesda, MD: National Association of School Psychologists.

Howes, C., Burchinal, M., Pianta, R., Bryant, D., Early, D., Clifford, R., \& Barbarin, O. (2008). Ready to learn? Children's pre-academic achievement in pre-kindergarten programs. Early Childhood Research Quarterly, 23, 27-50.

January, A. M, Casey, R. J., \& Paulson, D. (2011). A meta-analysis of classroom-wide interventions to build social skills: do they work? Social Psychology Review, 40, 242256.

Kramer, S. (2006). As crianças de 0 a 6 anos nas políticas educacionais no Brasil: Educação Infantil e/é fundamental. Educação \& Sociedade, 27(96), 797-818.

Landis, J. R., \& Koch, G. G. (1977). The measurement of observer agreement for categorical data. Biometrics, 33, 159-174.

Lane, K. L., Menzies, H. M., Bruhn, A., \& Crnobori, M. (2011). Managing challenging behaviors in schools: research-based strategies that work. New York: Guilford. 
Oliver, R. M., Wehby, J. H., \& Reschly, D. J. (2011). Teacher classroom management practices: effects on disruptive or aggressive student behavior. Nashville, Tennessee (USA): The Campbell Collaboration.

Pereira, M. E. M., Marinotti, M., \& Luna, S. V. (2004). O compromisso do professor com a aprendizagem do aluno: contribuições da Análise do Comportamento. In M. M. C. Hubner \& M. Marinotti (Orgs.), Análise do Comportamento para a Educação: contribuições recentes. (pp. 11-32), Santo André, SP: ESETec.

Pianta, R. C. (1998). Enhancing relationships between children and teachers. Washington, DC: American Psychological Association.

Pianta, R. C. (2011). Classroom management and relationships between children and teachers: implications for research and practice. In C. M. Evertson \& C. S. Weinstein (Orgs.), Handbook of classroom management. (pp. 685-709). New York: Routledge.

Regra, J. A. G. (2004). Aprender a estudar. In M. M. C. Hubner \& M. Marinotti (Orgs.), Análise do Comportamento para a Educação: contribuições recentes (pp. 225-242). Santo André, SP: ESETec.

Sidman, M. (2001). Coerção e suas implicações. Campinas, SP: Livro Pleno.

Skinner, B. F. (1972). Tecnologia do ensino. São Paulo, SP: Edusp.

Stasiak, G. R. (2010). Transição ao primeiro ano do ensino fundamental: percepção do estresse pelas crianças, suas características psicológicas e variáveis do seu contexto familiar (Dissertação de mestrado). Universidade Federal do Paraná, Curitiba, PR.

Stasiak, G. R. (2016). Avaliação sobre os Impactos do Programa Incredible Years Teacher Classroom Management às Professoras da Educação Infantil. Tese de doutorado, Universidade Federal do Paraná, Curitiba, PR, Brasil.

Sylva, K., Melhuish, E., Sammons, P., Siraj, I., Taggart, B., Smees, R., Toth, K., Welcomme, W., \& Hollingworth, K. (2014). Students' education and developmental outcomes at age 16: effective pre-school, primary and secondary education (EPPSE 3-16) project. Recuperado em 9 de abril de 2015, de www.ioe.ac.uk-research-153.html 
Tomaz, J. J. (2012). A reorganização do espaço para interações e brincadeiras na sala de Educação Infantil. In A. S. Coutinho, G. Day, \& V. Wiggers (Orgs.), Práticas pedagógicas na educação infantil: diálogos possíveis a partir da formação professional (pp. 101-116). São Leopoldo, RS: Oikos.

Vale, V. M. (2011). Tecer para não ter de remendar: o desenvolvimento socioemocional em idade pre-escolar e o programa Anos Incríveis para Educadores de Infancia. Tese de doutorado, Universidade de Coimbra, Coimbra, Portugal.

Vale, V., \& Gaspar, F. (2004). Fios e desafios da inteligência sócio-emocional: percepção dos educadores de infância sobre as suas estratégias de gestão do comportamento das crianças. Revista Portuguesa de Pedagogia, 38, 337-357.

Vasconcelos, L. A. (2003). Quem deseja uma criança que expressa opiniões? In F. C. S. Conte \& M. Z. S. Brandão (Orgs.), Falo ou não falo? Expressando sentimentos e comunicando ideias (pp. 111-128). Londrina, PR: Mecenas.

Viecili, J., \& Medeiros, J. G. (2002a). A coerção e suas implicações na relação professor aluno. Psico-USF, 7(2), 229-238.

Weber, L. N. D., Leite, C. R., Stasiak, G. R., Santos, C. A. S., \& Forteski, R. (2015). O estresse no trabalho do professor. Imagens da Educação, 5 (3), 40-52.

Webster-Stratton, C. (2008). How to promote children's social and emotional competence. London, England: Paul Chapman. 